\title{
Carbon footprint management of unconventional natural gas development in the export scenario
}

\author{
Sangita Bista*, Philip Jennings, and Martin Anda \\ School of Engineering and Information Technology, Murdoch University, Murdoch, WA 615, Australia
}

Accepted: 12 December 2018

\begin{abstract}
In Australia, exploitation of shale gas is at an early stage. Western Australia has estimated its technically recoverable gas resources at 235 trillion cubic feet (tcf). It is viewed as an exciting economic prospect and decarbonising option for transition to climate change mitigation. The central focus of this paper is to estimate the climate impacts of Australian shale gas fracking and compare with other energy sources. Electricity generation has been considered as end use of gas in export scenarios to Japan and China. Analysis has been done for resource development periods of 20 and 40 years. Carbon footprints of shale gas range from $604 \mathrm{MtCO}_{2} \mathrm{e}$ to 543 $\mathrm{MtCO}_{2} \mathrm{e}$ per annum for China and Japan export cases, respectively, for 20 years field lifetime, if 66 tcf of shale gas is exploited and used. This result is roughly equivalent to $115 \%$ of Australia's total national emissions for the year 2014. If all technically recoverable shale gas (235tcf) from the Canning Basin in the Kimberley is exploited and exported to China and Japan over 40 years, the annual emissions are double the total Australian national emissions. The result suggests that shale gas has low carbon intensity compared to coal and oil but solar PV and wind are much cleaner energy options for GHG mitigation. The solar PV and wind electricity would produce $8 \%$ and $5 \%$ of the shale gas electricity emissions, respectively. Unless accompanied by stringent regulation and compliance on the upstream resource development, stage shale gas cannot be an appropriate energy source for sustainable development as opposed to renewable energy sources.
\end{abstract}

\section{Highlights}

- First GHG impacts assessment of shale gas for LNG export scenarios to Japan and China

- Export to Japan has lower carbon footprints compared with China in scenarios under investigation

- Unconventional gas resources have lower GHGs emissions compared with the coal and fewer climate benefits compared with renewables

- When supported by stringent regulations, on shore shale gas fracturing can be a transitional energy source for GHG abatement.

\section{Introduction}

Shale gas is one of the most important unconventional gas resources in the energy mix. Its extraction involves the hydraulic fracturing technique [1], commonly known as "fracking". From the environmental perspective, the negative externalities of shale gas fracking need to be closely examined, especially the GHG impacts. The

\footnotetext{
* e-mail: s.bista@murdoch.edu.au
}

environmental impact of the extraction of unconventional gas sources remains under-researched, particularly in Australia. In terms of the potential impact of the GHG emissions from unconventional resources, there is a considerable ongoing debate [2-4]. There are elements of unconventional gas extraction that differ considerably from the typical conventional process [5]. Hence, it is important to estimate the life cycle emissions. This paper examines the environmental impact on climate change of a potential shale gas extraction project in Western Australia, in the Canning Basin of the Kimberley region. An analysis of the GHG emissions in terms of the carbon dioxide equivalent $\left(\mathrm{CO}_{2} \mathrm{e}\right)$ has been carried out and compared with renewable energy alternatives. A life cycle analysis (LCA) approach has been used to estimate the cradle to grave GHG emissions from shale gas.

In Australia, exploitation of shale gas is at an early stage. Western Australia has a very significant amount of on shore shale gas and thus new projects/proposals for shale gas development are underway. The hydraulic fracturing technique used to recover onshore shale and tight gas are claimed to have lower carbon emissions compared with other fossil fuels [6,7]. Thus, it is promoted as a clean transitional fuel for the next decades to combat climate change [8]. However, there has been a controversy 


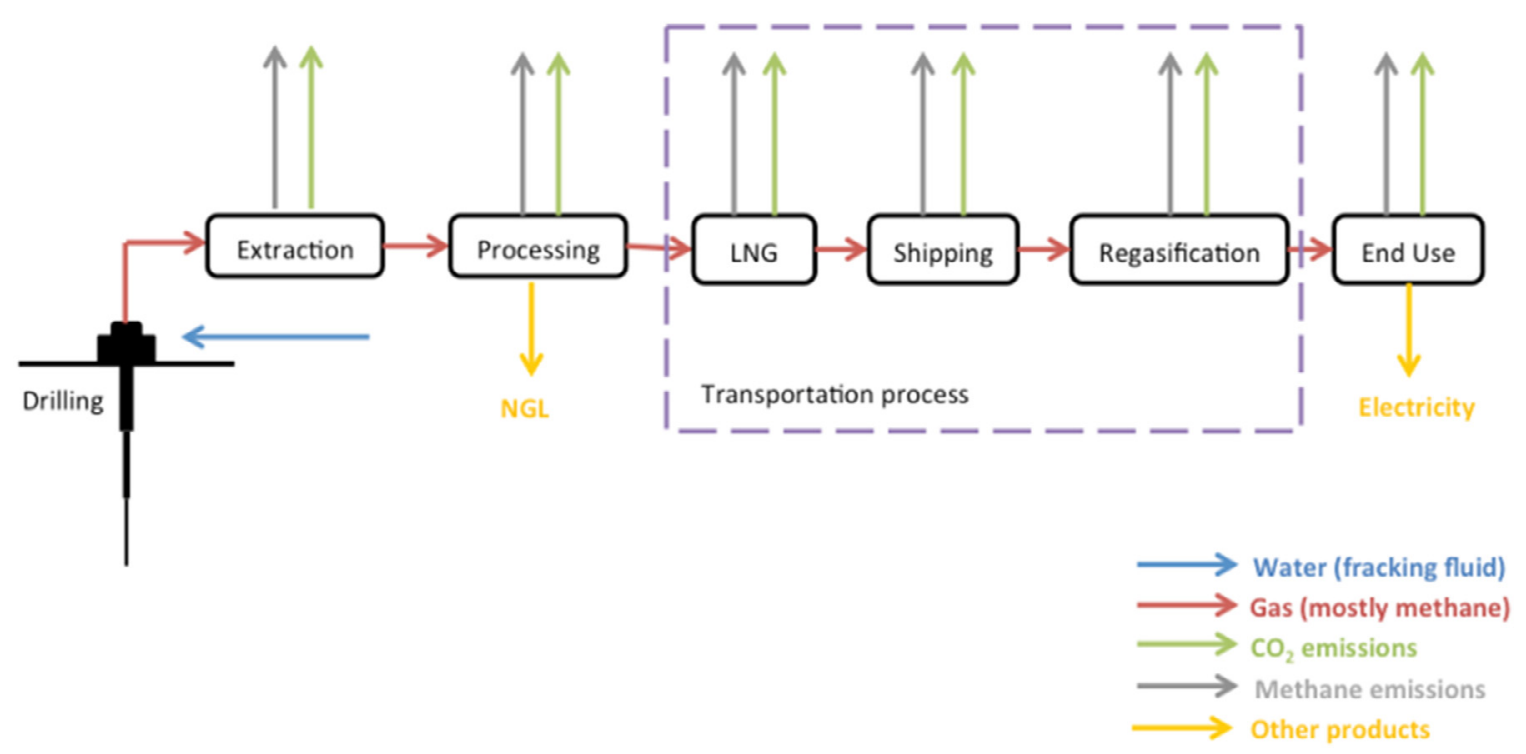

Fig. 1. Study boundary for LCA analysis of hydraulic fracking.

from local to federal level concerning GHG emissions from fracking in Australia. The controversy escalated due to the fact that the Victorian Government recently announced a ban on shale gas fracking [9]. To make sensible and balanced policy decisions on the promotion of climatefriendly energy resources, the GHG emissions from the lifecycle of shale gas have to be well understood. Therefore, this paper aims to address this issue of concern by comparing shale gas fracking emissions with those of other sources of energy. This study also includes a comparison of fracking emissions with Australia's national GHG emissions for various scenarios under investigation.

\subsection{Australia and the unconventional gas industry}

Australia is one of the largest exporters of natural gas to the Asia Pacific region [7,10]. Over the past 10 years, Australia has increased its proven gas reserves by one-third (IEA, 2012). It has expanded the gas industry horizon to include unconventional resources such as shale and tight gas, which were previously uneconomical [11]. The exploitation of coal seam gas (CSG) represents a large part of the Australian unconventional gas market and it represents $40 \%$ of Eastern Australian domestic gas production [10]. The Australian shale gas resources are certainly enormous [12], given that some researchers have claimed that the unproved technically recoverable shale gas resources are about 429 trillion cubic feet (tcf) in WA alone [13]. According to EIA [14], Japan is the largest Liquefied Natural Gas (LNG) importer and China is the second largest importer from Australia.

Unconventional gas is defined as "sources of gas trapped deep underground by impermeable rocks, such as coal, sandstone and shale" [13]. The three main types of "unconventional" gas are: shale gas (found in shale deposits); coal bed methane (CBM-extracted from coal beds) and tight sand gas (which is trapped underground in impermeable rock formations). These sources are mined using the hydraulic fracturing process. During this process, greenhouse gases (GHGs) including methane $\left(\mathrm{CH}_{4}\right)$ and carbon dioxide $\left(\mathrm{CO}_{2}\right)$ are released into the atmosphere as fugitives in well completion, flow back, drill outs and venting [15]. Indirect carbon dioxide emission happens through flaring, and the carbon dioxide is principally produced through combustion at the gas turbine, during the powering process or in flaring [16]. To date, only the United States has a well-established unconventional gas industry, which has seen unprecedented growth in recent years [17]. Not many studies have been carried out on this subject in Australia except for a background study on shale gas in WA by Bista et al. [18].

\subsection{Life cycle GHG assessment}

The GHG footprint is defined as the total GHG emission that occurs from developing and using the gas (EPA 2006). It is expressed as equivalents of carbon dioxide $\left(\mathrm{CO}_{2}-\mathrm{e}\right)$ per unit of energy obtained during combustion (EPA 2010). The ISO 14040 standard defines LCA as: $L C A$ is the compilation and evaluation of the inputs, outputs and the potential environmental impacts of a product system throughout its life cycle.

GHG emissions in tonnes of $\mathrm{CO}_{2}$-e were calculated based on the Inter-governmental Panel on Climate Change guideline (IPCC, 2007), using a 100-year lifespan for methane. To estimate GHG emissions from hydraulic fracking, inputs, outputs and end of life emissions of the entire gas production system have been accounted for in this study. Drilling, extraction processing, transportation and electricity production are part of the natural gas life cycle assessment in this study. All of these different stages release greenhouse gases such as methane $\left(\mathrm{CH}_{4}\right)$, hydrogen sulphide $\left(\mathrm{H}_{2} \mathrm{~S}\right)$, nitrogen dioxide $\left(\mathrm{NO}_{2}\right)$ or carbon dioxide $\left(\mathrm{CO}_{2}\right)$. The aim here is to estimate the climate impact (in terms of $\mathrm{CO}_{2}$-e) using the LCA approach. The LCA boundary of this study is shown in Figure 1. 


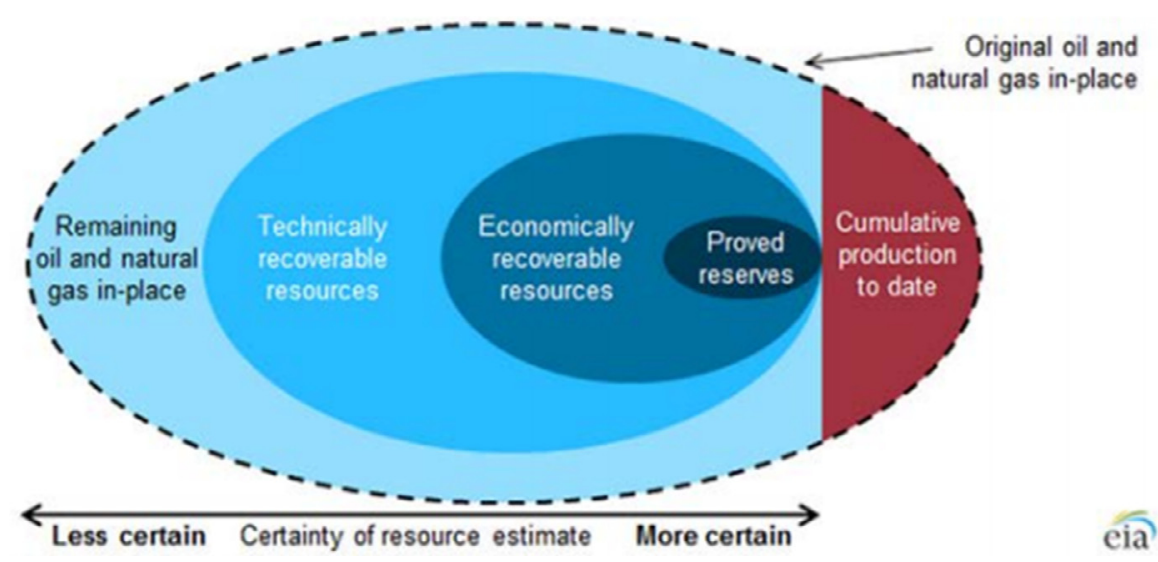

Fig. 2. Natural gas resource types (Energy Information Administration 2015).

\subsection{Types of natural gas resources}

To clarify the resource data that will be used in this paper, a little nomenclature is necessary. There is a difference between reserves and resources in the hydrocarbons sector. On the one hand, a resource is an estimate of how much hydrocarbon is in the ground, and on the other hand, the reserve is the amount of measured resources that could be expected to be economically mineable under the current economic and technological conditions [14]. In this way, gas reserves represent a small and variable percentage of gas resources, changing according to the price of the gas and the technology used to extract it. The resource category can be divided into several classes based on the exploration and technical and economic surveys that have been made to estimate the volume of gas in the rock. These classes are summarized in Figure 2. The class with most uncertainty in the amount of gas available is the "remaining natural oil and gas in place" and the most certain class is the "proved reserves" (the gas that it is definitely possible to extract economically).

In this paper, the "technically recoverable resources" will be the class that will be used for the estimation of the Kimberley resources.

\subsection{Hydraulic fracturing}

A vertical well is drilled into the ground until the shale layer is reached [19]. When the drilling is completed, a perforated pipe gun is sent down [12]. Explosives are then fired from the gun through the perforations into the shale. Fracturing fluid, a mixture of water (around 96.7\%), sand (also called proppant) (3.0\%) and chemicals (0.3\%) [20] is pumped from the surface down the wellbore and into the cracks [3]. Then fractures crack, expand and branch out allowing the natural gas to be extracted [15]. Sand is used to keep the fissures open and the chemicals limit the growth of bacteria and the corrosion in the well [21]. Because of the rock structure and for economic reasons (to recover more gas from the well), it is better to do horizontal drilling [12]. Once the drill reaches the level where the shale gas is located, it changes its direction and the hole is drilled horizontally into the shale [22]. Then the well is drilled vertically [23]. The fracking fluid is injected and it creates a way out for the shale gas trapped in the rock [12]. After the recovery of the fracking fluid, the gas can escape because of the pressure difference between the surface and the underground [24].

\section{Material and methods}

The aim is to evaluate the shale gas GHG emissions from shale gas extraction in the Kimberley to power generation in Japan or China. To do so, the entire life cycle is separated into two sections: gas production, and use (Fig. 3). Gas production includes extraction and processing, and gas use includes distribution and power generation as illustrated in the model in Figure 3.

The scenarios under investigation are either best case: $100 \%$ (235 tcf) of the gas resource is extracted or worst case: only $28 \%$ (66 tcf) is extracted (please refer to Tab. 1 ). The exploitation of $100 \%$ shale gas is best from the economic perspective and thus is defined as the best case.

This study has employed three different methods to estimate the "gas production" emissions. The emissions from the "end use" have been estimated separately using the standard factors for China and Japan. The three methods for the "gas production" category are found in the literature and applied to the Canning Basin, resources. The aim here is to compare them and obtain an average to balance the final result, which is the GHG emission from cradle to grave of shale gas. The first method includes a summary of all the information and the emission factors found in different literatures. It gives a rough size of the GHG emissions if all the Kimberley's shale gas resources are used. The second and the third methods involve an in-depth and complex review of the different sources of greenhouse gases during the process (extraction to distribution). In all methods, the aim is to estimate the shale gas emissions from extraction to processing. Consequently, an average value from all three methods is computed to get an average $\mathrm{CO}_{2}$ e emission, to reflect the impact of shale gas fracking in the Canning Basin. 


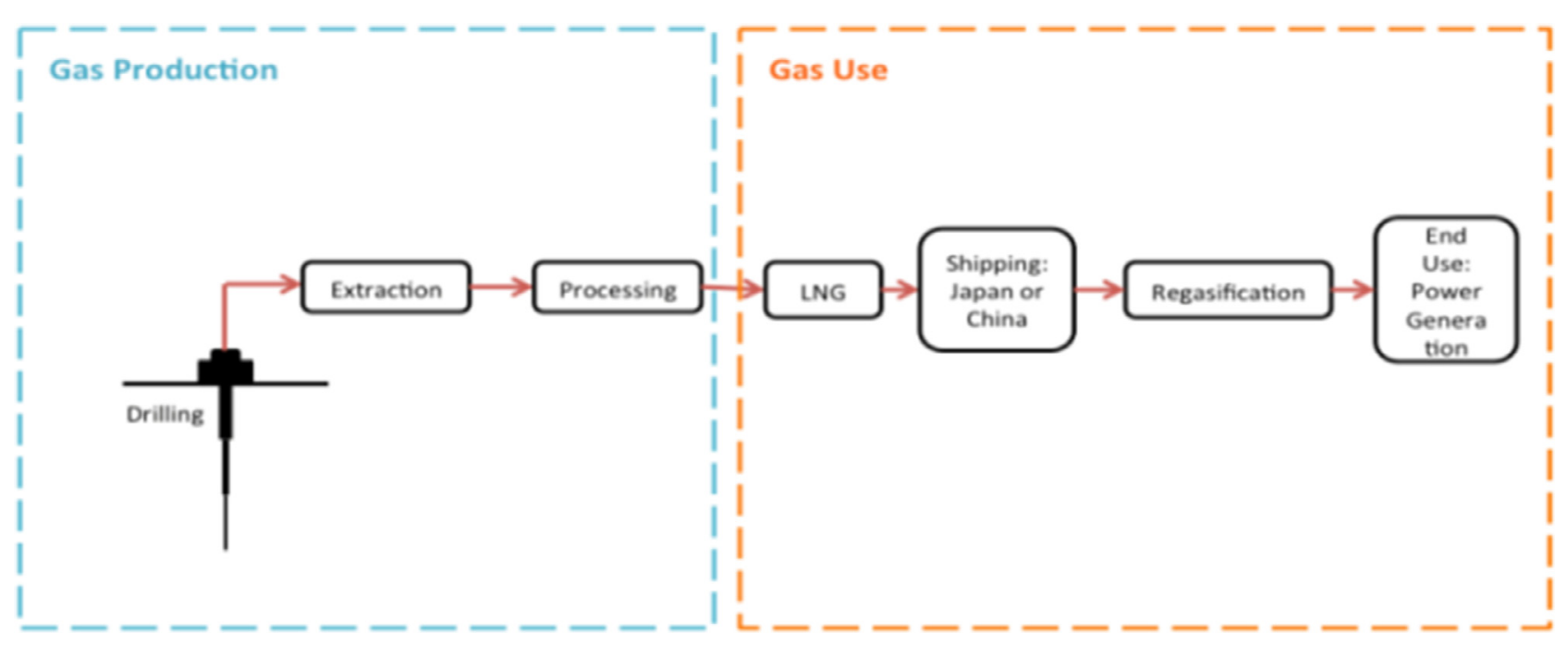

Fig. 3. Separation of shale gas life cycle into two sections (Goldstein et al. 2012).

Table 1. Scenarios under investigation.

\begin{tabular}{ll}
\hline Scenarios & Conditions \\
\hline Best case & If 235 tcf of the resource is extracted, \\
(Case 1$)$ & based on DMP estimated resource \\
Worst case & If 66 tcf of the resource is extracted, \\
(Case 2$)$ & based on proven reserves \\
\hline
\end{tabular}

Method 1: This method separates the methane emissions into three categories according to the time they happened. There are upstream, midstream and downstream emissions. The upstream emissions include leaks and emissions at the well site. The midstream emissions are from the processing of the gas. The downstream emissions include the storage systems, and the transmission and distribution via pipelines. Average factors for upstream, downstream and midstream have been estimated based on references $[15,25-30]$. The data used are summarized in Table 2 (refer to Annex 1 in Supplementary materials).

Method 2: The second method uses conventional and international data from the IPCC Guidelines for National Greenhouse Gas Inventories (2006) and reference [31]. The emission factors are from IPCC Guidelines for National Greenhouse Gas Inventories (2006) compared with another study specific to unconventional gas for IPCC in 2013. The differences between the emissions from conventional and unconventional gas from workovers and well completion during the gas extraction stages are calculated using the Glancy [31] formula:

$$
E_{\text {unconv }}=E_{\text {conv }}+E_{\text {comps } / \text { works }}
$$

where

$E_{\text {unconv }}=$ Fugitive emissions from unconventional gas sources
Table 2. Emission factors from upstream, midstream and downstream sources.

\begin{tabular}{lll}
\hline Range & $\begin{array}{l}\text { Factor from } \\
\text { upstream } \\
\text { and midstream } \\
\text { emission (\%) }\end{array}$ & $\begin{array}{l}\text { Factor from } \\
\text { downstream } \\
\text { emission }(\%)\end{array}$ \\
\hline Low & 0.60 & 0.07 \\
High & 3.30 & 2.50 \\
Average & 2.24 & 1.00 \\
\hline
\end{tabular}

$E_{\text {conv }}=$ Fugitive emissions from conventional gas sources

$E_{\text {comps } / \text { works }}=$ Fugitive emissions from completions and workovers

Method 3: Relevant emission factors were reviewed and synthesized from the literature [23,26,29,32,33], and an average value was used to estimate the emissions. Most of the data used are from the U.S. database as database on fracking in Australia is yet to be established for the public domain. In every point source emissions calculation, each time a certain amount of methane is released, the volume of the resource reduces. Therefore, we have calculated an "actual volume" according to the following formula:

$$
V_{\text {actual }}=V_{\text {last }}-V_{\text {lost }}
$$

Where

$V_{\text {actual }}=$ actual volume used in the next calculations,

$V_{\text {last }}=$ last volume used,

$V_{\text {lost }}=$ lost volume of gas from the previous step.

The stages considered are well completion, well underground containment failure, flaring, venting and gas processing (refer to the supplementary material for the calculations and the data used). 


\subsection{Data uncertainty}

Some unconventional wells would have been completed using best practices resulting in low completion emissions. On the contrary, some wells would have been completed with poor practices resulting in high completion emissions. However, there is no room for claiming that a more recent, larger sampling of natural gas wells would increase or decrease the emission factors used in this study as the paper has used an average estimate sources based on the most similar gas fields. Further, data analysis has not included the embedded emissions of well construction, internal material transport emissions say from Perth to the Canning Basin, for example in the upstream emission. Also, the emissions from accidents and emergencies, emissions from workover are not included. These primary data (such as \% methane leaks, contaminations) from petroleum companies are not readily available in Australia, because shale gas technologies and exploitation are new in Australia. Official reports and studies such as the Australian Greenhouse Emissions Information System (AGEIS) are incomplete on this subject. Yet, to understand if this energy source contributes to sustainable development in the context of climate change mitigation is of paramount importance. Simultaneously, it is important to acknowledge that LCA is an iterative process, modelling results undergo necessary updates when new data become available, thus filling current data gaps.

\section{Results}

\subsection{Average emission results (extraction to processing)}

In this section, the results obtained from all three methods used in this study have been averaged for increased accuracy. The supplementary material presents average values from each of the methods used and a final average value over all three methods, which is the final result for the emissions from extraction to processing of shale gas by fracking in the Canning Basin. During venting, the natural gases associated with gas production are released directly to the atmosphere. Under current legislation (at the time of this research), venting is permitted in WA. So, it is important to estimate how much $\mathrm{CO}_{2} \mathrm{e}$ would be vented into the atmosphere from fracking. A total emission of 4933 $\mathrm{MtCO}_{2} \mathrm{e}$ is estimated considering venting and 4066 $\mathrm{MtCO}_{2} \mathrm{e}$ without venting for the extraction and processing of $235 \mathrm{tcf}$ of shale gas. This analysis is for both cases under consideration. This includes the emissions from extraction to processing of shale gas produced using the fracking technique in the Canning Basin of Western Australia (refer to the supplementary material for the graph). The end use emissions are calculated separately. It is estimated that the emissions gap between the non-venting and venting cases is about $867 \mathrm{MtCO}_{2} \mathrm{e}$, which is only about $2 \%$ of the average value of the entire GHG emissions (from extraction to power generation). Therefore, only the case with venting is considered for the rest of the analysis as venting is permitted in WA. Figure 4 shows the GHG emissions with and without the venting for the production of shale gas. They are expressed in terms of mega tonnes $(\mathrm{Mt})$ of $\mathrm{CO}_{2} \mathrm{e}$.

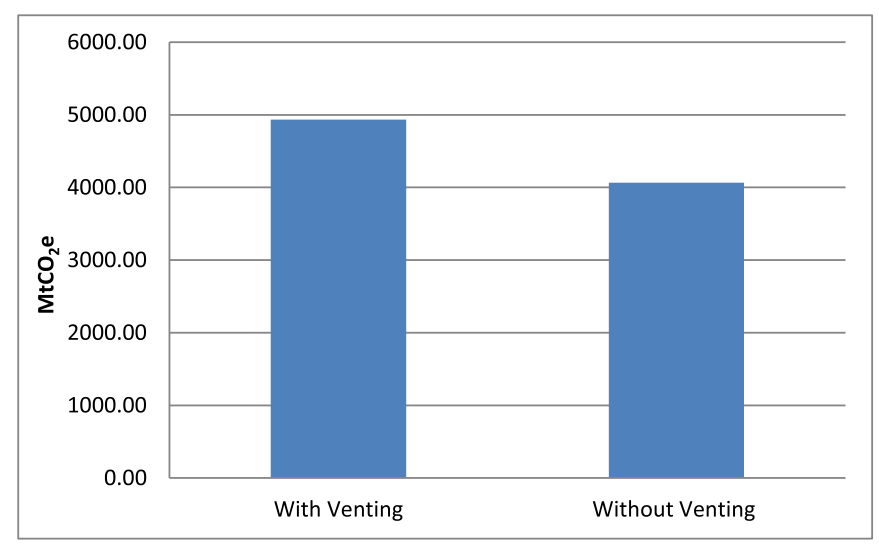

Fig. 4. Production emissions with and without venting for extraction of $235 \mathrm{tcf}$ of shale gas.

\subsection{Emissions from end use}

The end use includes emissions from LNG processing, shipping and transport to Japan or China, ${ }^{1}$ regasification and power generation. Natural gas can serve as fuel for power generation, for heating or for cooking. The power generation process includes burning the gas in a gas turbine to produce heat and electricity. The GHG emissions during this process correspond to the natural gas combustion products. The emissions from electricity generation have been estimated using the latest data and factors in an Australian context for an export scenario to China and Japan (refer to Fig. 5).

\subsubsection{Emission comparison between gas development (extractive emission) and power generation}

The total emissions when the gas is exported to China are between 33963 and $53616 \mathrm{MtCO}_{2} \mathrm{e}$ for the whole resource (235 tcf). The average value is $43153 \mathrm{MtCO}_{2} \mathrm{e}$. For the Japan case, the life cycle emissions are between 32511 and $46321 \mathrm{MtCO}_{2} \mathrm{e}$ with a mean value of $38779 \mathrm{MtCO}_{2}$-e as presented in Table 3.

It is found that the emissions are higher in the China export scenario; the difference is about $4373 \mathrm{MtCO}_{2} \mathrm{e}$. This is because the power turbines used in Japan are more efficient than those used in China [34]. Power generation represents the major part of the greenhouse gas emissions accounting for $76 \%$ and $74 \%$ for the cases of export to China and Japan, respectively. It shows that the emissions from power generation dominate in both scenarios. These results are consistent with and similar to those in some reports in reference [5], showing the important impact of power generation in the natural gas GHG life cycle.

\footnotetext{
${ }^{1}$ These two countries are well known to import LNG gas from Australia (Department of Foreign Affairs and Trade - Australian Government, 2015).
} 


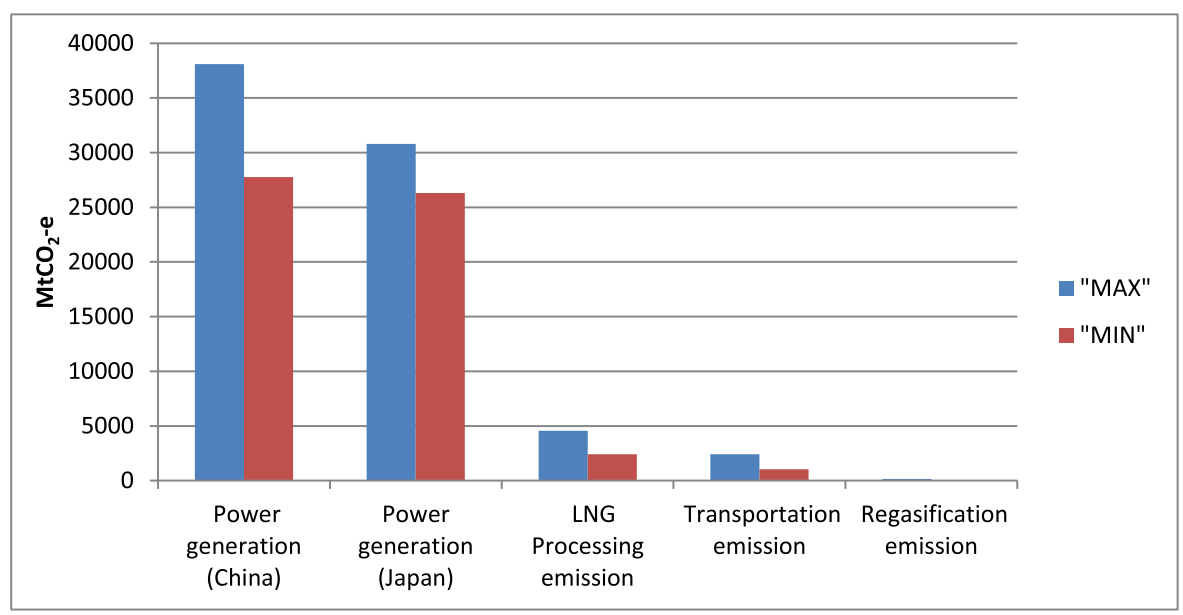

Fig. 5. End use emissions comparison for 235 tcf of shale gas.

Table 3. Total emissions from extraction to power generation $\left(\mathrm{MtCo}_{2} \mathrm{e}\right)$ for $235 \mathrm{tcf}$ of shale gas.

\begin{tabular}{llll}
\hline Range & $\begin{array}{l}\text { China } \\
(235 \mathrm{tcf})\end{array}$ & $\begin{array}{l}\text { Japan } \\
(235 \mathrm{tcf})\end{array}$ & Remarks \\
\hline Max & 53616 & 46321 & $\begin{array}{l}\text { 4374 } \mathrm{MtCO}_{2} \mathrm{e} \text { higher } \\
\text { emissions in case } \\
\text { of China }\end{array}$ \\
Min & 33963 & 32511 & \\
Average & 43153 & 38779 & \\
\hline
\end{tabular}

\section{Discussion}

The lifetime of a gas field is about $20-30$ years [35]. Since $235 \mathrm{tcf}$ is a lot of shale gas compared to the most established gas industry in the U.S. situation, extracting $235 \mathrm{tcf}$ in only 30 years seems to be unrealistic. Therefore, the upper limit for the lifetime of the field is considered to be 40 years. In the meantime, the technology, the law, the permits or the global energy situation could change. Thus, the gas exploitation could last for less than 40 years too. Therefore, the lower limit is set to be 20 years. Yearly emissions have been calculated if the resource is exploited over 20 or 40 years. There will be emission of $604 \quad \mathrm{MtCO}_{2} \mathrm{e} /$ year throughout the 20 years life of the field if $66 \mathrm{tcf}$ of shale gas is developed and exported to China. Similarly, 543 $\mathrm{MtCO}_{2} \mathrm{e}$ per year if the same amount of shale gas is exported to Japan over 20 years. This is roughly equivalent $(115 \%)$ to Australia's total national emissions for the year 2014, which were $525 \mathrm{MtCO}_{2} \mathrm{e}$ [36]. Likewise, if the same amount of gas is extracted over 40 years, the annual emissions are estimated to be $302 \mathrm{MtCO}_{2} \mathrm{e}$ and 271 $\mathrm{MtCO}_{2} \mathrm{e}$, respectively, for China and Japan export scenarios, which is equivalent to slightly more than half (58\%) of the total Australian national GHG emissions for 2014 (refer to Fig. 6). Similarly, if the entire field (235 tcf) is exploited over 20 or 40 years, the life cycle GHG emissions

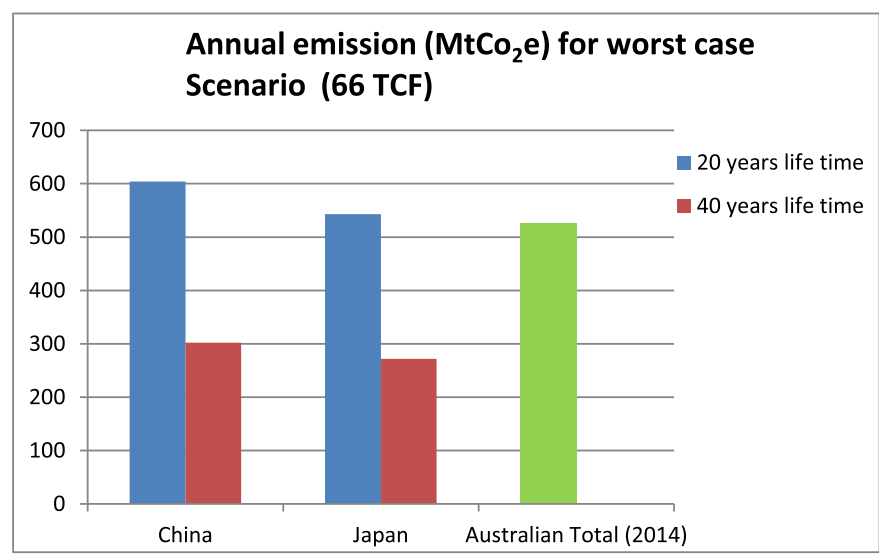

Fig. 6. Comparison with Australian national GHG emissions (2014) in worst case scenario.

will be correspondingly larger, as shown in Figure 7. In the case of export to China, over 20 years, the annual GHG emissions will be $2100 \mathrm{Mt} \mathrm{CO}_{2}$-e or roughly four times Australia's total national GHG emissions in 2014.

The emissions results for shale gas in this paper are compared with those of natural gas, coal, oil, nuclear, hydroelectricity, wind and solar PV (refer to Tab. 4). After a review of the literature, an average of different emission factors has been made and applied to the Kimberley case. The highest emissions are from coal followed by petroleum (oil). Coal energy produces about 1.5 times more GHG emissions than shale gas per kWh of electricity. Renewable energy and nuclear energies have the lowest emissions. Shale gas has the third largest GHG emissions. The LCA data for other sources of electricity are sourced from work in the literature as indicated in Table 3.

Table 3 shows a significant difference in GHG emissions between shale gas energy and other alternative energy sources. The wind power life cycle emissions represent about $5 \%$ of the shale gas power generation emissions for the equivalent amount of electrical energy. Shale gas emission is slightly lower than coal and oil, which could 


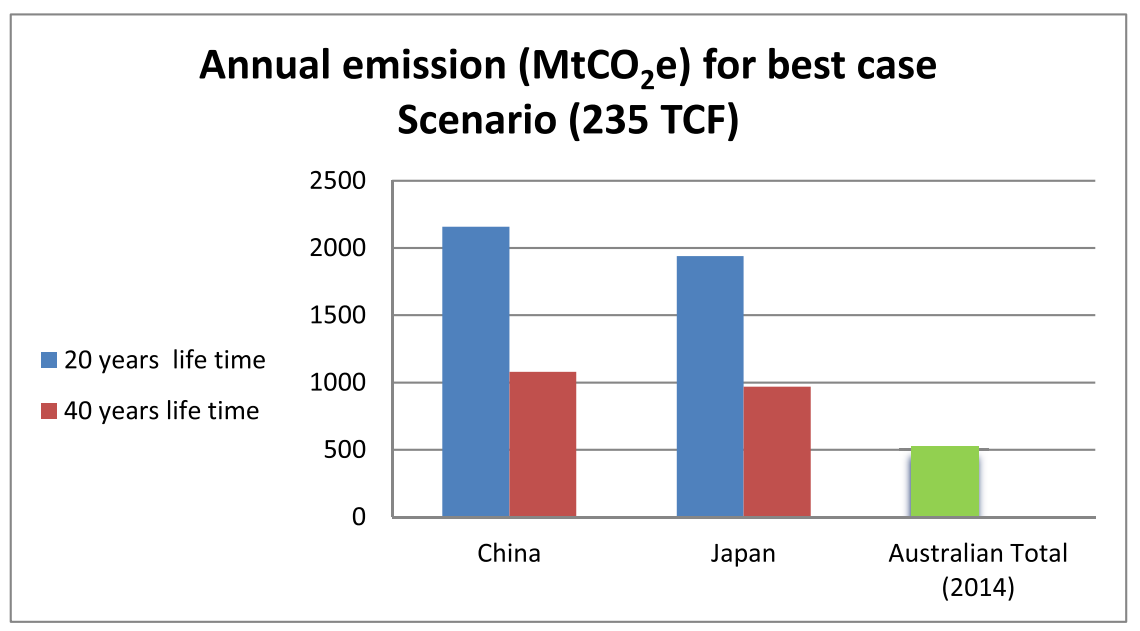

Fig. 7. Comparison with Australia's national GHG emissions (2014) in best case scenario.

Table 4. Mean greenhouse gas emissions $\left(\mathrm{gCO}_{2} \mathrm{e} / \mathrm{kWh}\right)$.

\begin{tabular}{lll}
\hline Energies & Value $\left(\mathrm{gCO}_{2} \mathrm{e} / \mathrm{kWh}\right)$ & Reference \\
\hline Coal & 960 & Hayhoe, Kheshgi [37] \\
Oil (petroleum) & 778 & Hayhoe, Kheshgi [37] \\
Shale gas & 614 & This study \\
Offshore natural gas & 548 & Hertwich, Gibon [38] \\
Nuclear & 66 & Nugent and Sovacool [39] \\
PV Solar & 50 & Nugent and Sovacool [39] \\
Wind & 34 & Nugent and Sovacool [39] \\
Hydroelectricity & 13 & Nugent and Sovacool [39] \\
\hline
\end{tabular}

vary if we use the GWP20 for methane fugitives from shale gas development. The GWP of methane after 20 years is 86 , while after 100 years it is 25 [40].

\section{Conclusion}

Compared with most alternative energy sources, shale gas emissions are high. It is estimated that the GHG emissions from shale gas range from $604 \mathrm{MtCO}_{2} \mathrm{e}$ to $543 \mathrm{MtCO}_{2} \mathrm{e}$ per annum for China and Japan export cases, respectively, for 20 years lifetime of the field under the worst-case scenario from a mining perspective. This result is roughly equivalent $(115 \%)$ to Australia's total national emissions for the year 2014, which were $525 \mathrm{MtCO}_{2} \mathrm{e}$. It is estimated that the solar PV and wind electricity would produce $8 \%$ and $5 \%$ of the shale gas electricity emissions, respectively. This paper concludes that shale gas fracking in Western Australia for electricity generation has higher GHGs emissions as opposed to the renewables. However, it has lower GHGs emissions compared with the coal. In addition, this paper has not examined the economic benefits of such operations against the environmental cost of hydraulic fracturing in Western Australia. This paper suggests doing more studies on the economic versus ecological benefits to better understand the promotion of shale gas fracking in Australia.

\section{References}

1. J.P. Barnett, Life Cycle Assessment (LCA) of Liquefied Natural Gas (LNG) and its environmental impact as a low carbon energy source, in Environmental Engineering (University of Southern Queensland, Queensland, 2010), p. 55

2. T. Clark, R. Hynes, P. Mariotti, Greenhouse Gas emissions study of Australian CSG to LNG (WorleyParsons, Australia, 2011)

3. R. Michalski, A. Ficek, Environmental pollution by chemical substances used in the shale gas extraction - a review, Desalin. Water Treat. 57, 1336 (2016)

4. Parliament WA, Inquiry into the Implications for Western Australia of Hydraulic Fracturing for Unconventional Gas (2013)

5. P.E. Hardisty, T.S. Clark, R.G. Hynes, Life cycle greenhouse gas emissions from electricity generation: a comparative analysis of Australian energy sources, Energies 5, 872 (2012) 
6. P. Cook et al., Engineering Energy: Unconventional Gas Production (Australian Council of Learned Academies (ACOLA), Australia, 2013)

7. S. Jenner, A.J. Lamadrid, Shale gas vs. coal: Policy implications from environmental impact comparisons of shale gas, conventional gas, and coal on air, water, and land in the United States, Energy Policy 53, 442 (2013)

8. C. Tagliaferri et al., Shale gas: a life-cycle perspective for UK production, Int. J. Life Cycle Assess. 1 (2016)

9. N. ABC, Victorian unconventional gas exploration ban to end fracking and CSG extraction, in $A B C$ (ABC, Perth, WA, 2016)

10. Australian Government, Australia's Liquefied Natural Gas (LNG) exports, 2003-04 to 2013-14 and beyond (2015). Available from: https://dfat.gov.au/about-us/publications/ Documents/australias-lng-exports-2003-04-to-2013-14.pdf (accessed 25 July, 2016)

11. P. Cook et al., Engineering Energy: Unconventional Gas Production (2013)

12. CSIRO, What is hydraulic fracturing (2015). Available from: http://www.csiro.au/en/Research/Energy/Hydraulic-frac turing/a-What-is-hydraulic-fracturing (accessed 7 October, 2016)

13. Energy Information Administration, Technically Recoverable Shale Oil and Shale Gas Resources: Australia (USEPA, 2015), p. 57

14. EIA, Annual Energy Outlook 2016 (Independent statistics and analysis, 2016). Available from: https://www.eia.gov/ forecasts/aeo/tables_ref.cfm (accessed 21 September, 2016)

15. R. Howarth, R. Santoro, A. Ingraffea, Methane and the greenhouse-gas footprint of natural gas from shale formations, Clim. Change 106, 679 (2011)

16. R.W. Howarth, R. Santoro, A. Ingraffea, Venting and leaking of methane from shale gas development: response to Cathles et al., Clim. Change 113, 537 (2012)

17. M. Binnion, How the technical differences between shale gas and conventional gas projects lead to a new business model being required to be successful, Mar. Pet. Geol. 31, 3 (2012)

18. S. Bista, P. Jennings, M. Anda, Cradle to grave GHG emissions analysis of shale gas hydraulic fracking in Western Australia, Renew. Energy Environ. Sustain. 2, 45 (2017)

19. I.D. Posen, P. Jaramillo, W.M. Griffin, Uncertainty in the Life Cycle Greenhouse Gas Emissions from U.S. Production of Three Biobased Polymer Families, Environ. Sci. Technol. 50, 2846 (2016)

20. Z.P. Bažant et al., Why fracking works, J. Appl. Mech. 81, (2014). DOI: 101010-101010-10

21. Geoscience News and Information, What is frac sand (2016), $2 / 2017$

22. EPA, Hydraulic Fracturing of Gas Reserves (G.o.W. Australia, 2011), p. 4

23. G.A. Heath et al., Harmonization of initial estimates of shale gas life cycle greenhouse gas emissions for electric power generation, Proc. Natl. Acad. Sci. 111, E3167 (2014)
24. ACOLA, Potential Geological Risks Associated with Shale Gas Production in Australia (2013), p. 50

25. USEPA, Greenhouse gas emissions reporting from the petroleum and natural gas industry (2010). Available from: https://www.epa.gov/sites/production/files/2015-05/docu ments/background-tsd-posted-4-12-10-epa-hq-oar-20090923-0027.pdf (accessed 2018)

26. A. Burnham et al., Life-cycle greenhouse gas emissions of shale gas, natural gas, coal, and petroleum, Environ. Sci. Technol. 46, 619 (2012)

27. L.M. Cathles et al., A commentary on "The greenhouse-gas footprint of natural gas in shale formations" by R.W. Howarth, R. Santoro, and Anthony Ingraffea, Clim. Change 113, 525 (2012)

28. G. Pétron et al., Hydrocarbon emissions characterization in the Colorado Front Range: A pilot study, J. Geophys. Res.: Atm. 117 (2012)

29. H. Nathan et al., The greenhouse impact of unconventional gas for electricity generation, Environ. Res. Lett. 6, 044008 (2011)

30. T. Stephenson, J.E. Valle, X. Riera-Palou, Modeling the relative GHG emissions of conventional and shale gas production, Environ. Sci. Technol. 45, 10757 (2011)

31. R. Glancy, Quantifying Fugitive Emission Factors from Unconventional Natural Gas Production Using IPCC Methodologies (Institute for Global Environmental Strategies, Japan, 2013), p. 45

32. NETL, Life Cycle Greenhouse Gas Inventory of Natural Gas Extraction, Delivery and Electricity Production (US Department of Energy, 2011)

33. NREL, US Life Cycle Inventory Databases (2017). Available from: http://www.nrel.gov/lci/

34. C. Munnings, A.J. Krupnick, Comparing Policies to Reduce Methane Emissions in the Natural Gas Sector (2017). Available from: http://www.rff.org/research/publications/ comparing-policies-reduce-methane-emissions-natural-gassector (accessed 10 July, 2017)

35. A. King, Submission Concerning the Impacts of Hydrolic Fracturing in Western Australia (Sustainable Energy Now, West Perth, 2013), pp. 2-3

36. D.o.t.E.a.E. Australian Government, Australian Greenhouse Emissions Information System (2016). Available from: http://ageis.climatechange.gov.au/

37. K. Hayhoe et al., Substitution of natural gas for coal: climatic effects of utility sector emissions, Clim. Change 54, 107 (2002)

38. E.G. Hertwich et al., Integrated life-cycle assessment of electricity-supply scenarios confirms global environmental benefit of low-carbon technologies, Proc. Natl. Acad. Sci. 112, 6277 (2015)

39. D. Nugent, B.K. Sovacool, Assessing the lifecycle greenhouse gas emissions from solar PV and wind energy: A critical metasurvey, Energy Policy 65, 229 (2014)

40. IPCC, Climate change 2007, in Synthesis Report (WMO \& UNEP, Geneva, Switzerland, 2007)

Cite this article as: Sangita Bista, Philip Jennings, Martin Anda, Carbon footprint of unconventional gas development under the export scenarios, Renew. Energy Environ. Sustain. 4, 3 (2019) 